\title{
Heat therapy for cutaneous leishmaniasis elicits a systemic cytokine response similar to that of antimonial (Glucantime) therapy
}

\author{
Iza M.F. Lobo ${ }^{a}$, Milena B.P. Soares ${ }^{b}$, Tania M. Correia ${ }^{b}$, \\ Luiz A.R. de Freitas ${ }^{b}$, Maria Ines Oliveira ${ }^{a}$, Maria Nakatani ${ }^{a}$, \\ Eduardo Netto ${ }^{a}$, Roberto Badaro ${ }^{a}$, John R. David ${ }^{c, *}$ \\ a Universidade Federal de Bahia, Salvador, Bahia, Brazil \\ b Centro de Pesquisas Gonçalo Moniz, FIOCRUZ, Salvador, Bahia, Brazil \\ c Harvard School of Public Health, Boston, MA, USA
}

Received 4 June 2005; received in revised form 9 August 2005; accepted 12 August 2005 Available online 4 November 2005

\section{KEYWORDS \\ Leishmaniasis; \\ Cutaneous \\ leishmaniasis; \\ Heat therapy; \\ Cytokine; \\ Brazil}

\begin{abstract}
Summary Controlled heat delivered as radio waves has been used successfully in the treatment of cutaneous leishmaniasis (CL). Here we investigated whether local heat therapy has systemic effects, as measured by the modulation of cytokine production following heat therapy of CL lesions compared with antimonial (Glucantime) treatment. Patients with CL were randomly assigned into this study. Heat $\left(50^{\circ} \mathrm{C}\right.$ for $\left.30 \mathrm{~s}\right)$ was applied once. The control group received Glucantime therapy for $20 \mathrm{~d}$. Cytokine production by peripheral blood mononuclear cells was assayed on days 0,14 and 28 after onset of treatment. At the end of $28 \mathrm{~d}, 75 \%$ of lesions were healing or healed in the heat therapy group and $90 \%$ in the control group $(P=0.1261)$. There was a decrease in IFN- $\gamma, \mathrm{IL}-5$ and TNF- $\alpha$ levels comparing day 0 with day 28 in both groups, but no difference between the two therapy groups. In patients with only one of several lesions treated with heat therapy, the untreated lesions also healed. Local heat therapy in CL lesions leads to systemic cytokine responses similar to that induced by systemic Glucantime therapy. (c) 2005 Royal Society of Tropical Medicine and Hygiene. Published by Elsevier Ltd. All rights reserved.
\end{abstract}

\footnotetext{
* Corresponding author. Present address: 300 W. 23rd Street, Apt 13K, New York, NY 10011, USA. Tel.: +1 2124148646.

E-mail address: jdavid@hsph.harvard.edu (J.R. David).
}

\section{Introduction}

Heat therapy for cutaneous leishmaniasis $(\mathrm{CL})$ has been reported for half a century. da Silveira and Brener (1950) described the healing of a patient with $\mathrm{CL}$ and one with mucocutaneous leishmaniasis (MCL) 1 month after heat induced by Haemophilus ducreyi injections. In-vitro studies showed the sensitivity of various New and Old World 
Leishmania species to heat (Berman and Neva, 1981; Sacks et al., 1983). Subsequently, Neva et al. (1984) showed that diffuse cutaneous leishmaniasis $(D C L)$, but not $C L$, responded to heated water treatment at $39-41^{\circ} \mathrm{C}$. Junaid (1986) treated $\mathrm{CL}$ with infrared at $55^{\circ} \mathrm{C}$ for $5 \mathrm{~min}$ and also reported the healing of non-treated lesions in the treated patients. Aram and Leibovici (1987) observed healing of CL with ultrasound-induced heat. Navin et al. (1990) carried out a control trial using the original ThermoSurgery ${ }^{\circledR}$ instrument in Guatemala. Twenty-two patients received antimonial; 22 received 3 -weekly heat treatments of $50{ }^{\circ} \mathrm{C}$ for $30 \mathrm{~s}$; and 22 served as placebo controls. Three-quarters of the patients in the study had Leishmania (Viannia) braziliensis infection. Healing was similar in the two therapy groups, which was faster than in the placebo group. Velasco-Castrejon et al. (1997) carried out a feasibility study using the same instrument in Mexico on 201 patients with CL. A single application of $50{ }^{\circ} \mathrm{C}$ for $30 \mathrm{~s}$ across the anesthetized lesion was used, and resulted in over $90 \%$ healing.

CL caused by L. (V.) braziliensis can metastasize, leading to mucocutaneous leishmaniasis (MCL) (Marsden, 1986). Patients with $C L$ and $M C L$ have an inflammatory reaction in the lesions and a strong delayed-type hypersensitivity (DTH) response associated with IFN- $\gamma$ and TNF- $\alpha$ production (Ribeiro-de-Jesus et al., 1998). By contrast, DCL patients lack the inflammatory response, have no DTH response and diminished Th1 cytokines (Bomfim et al., 1996; Melby et al., 1989). The purpose of this study was to determine whether healing of CL caused by local heat therapy induced by radio waves was associated with a modulation of systemic cytokine responses compared with Glucantime therapy, the standard treatment for $\mathrm{CL}$ in Brazil.

\section{Materials and methods}

\subsection{Patients}

Between March 1997 and December 2000, the same physician in a health care clinic in Laje attended patients from Laje and neighborhood towns in the Jiquiriçá Valley, in the southwest of Bahia State, Brazil. At the first visit, the physician determined the clinical status of the patients. When they met the inclusion category described below, tests were done to confirm the diagnosis of CL. A Montenegro skin test was applied on the volar surface of the forearm and the cutaneous reaction measured $48 \mathrm{~h}$ later; a blood sample $(3-5 \mathrm{ml})$ was drawn for leishmanial serology and a biopsy of the lesion was obtained. If the lesion had a secondary infection, it was treated with local antibiotics before therapy was initiated.

The criteria for inclusion and exclusion were as follows: for inclusion, patients had to be at least 18 years old, have no more than two cutaneous lesions and none larger than $10 \mathrm{~cm}$. They had to have no signs and/or symptoms of mucous leishmanial involvement and no previous history of leishmaniasis or specific leishmanial treatment. The patients had to be willing to return for clinical and laboratory evaluation 14 and $28 \mathrm{~d}$ after initiating treatment and continue for clinical follow-up. After receiving a detailed explanation of the procedures to be carried out, they all signed an informed consent form. Pregnant patients were excluded, as were those who had contraindications for meglutamine antimonate (Glucantime; Rhodia) treatment, such as severe renal or cardiovascular disease. The protocol was approved by the IRB of the FIOCRUZ, Federal University of Bahia and Harvard School of Public Health.

Sixty-seven patients were screened for this study, but 30 did not meet the inclusion criteria as stated above. The remaining 37 patients were randomly placed into two groups, 17 receiving heat therapy and 20 receiving Glucantime.

\subsection{Design of the study}

The study protocol was designed to compare the success of the treatment at the end point of $28 \mathrm{~d}$, as any systemic effects should have appeared during this time. Afterward, all patients in the heat therapy group received standard 20 d Glucantime therapy independently of how well they had responded. The potential risk of future $M C L$ in patients submitted only to heat therapy precluded the proper evaluation of the individual response to heat therapy alone, until we could determine whether this therapy had a systemic effect in addition to the local one. The design of the study took into consideration that it is unethical to treat a group having $L$. (V.) braziliensis with a placebo.

At day 0 , patients included in the study with a presumptive diagnosis of CL (as determined by a positive skin test and positive serology) were randomly assigned to the heat therapy or Glucantime treatment groups. The diagnosis was confirmed by biopsy of the lesion. Physical examination of the patient included visualization of the nasal and oropharyngeal mucosa and checking for lymphadenopathy. The skin lesions were described in detail, including their number (one or two), location and size (expressed in $\mathrm{mm}$, great axis + small axis/2); the duration and clinical evidence of bacterial superinfection was noted, and a photograph of the lesion was taken. A venous blood sample $(20 \mathrm{ml})$ was collected to determine cytokine responses. Biopsy using a 4-mm punch pointed toward the ulcer border was done and the specimen was divided, with part put in $10 \%$ solution of formaldehyde and part frozen in liquid nitrogen.

\subsubsection{Heat therapy}

This was given in a single session. The lesion was washed with saline, then iodine and anesthetized with $2 \%$ lidocaine. The fork-like applicator of the ThermoSurgery instrument, powered by batteries, was placed at the edge of the lesion pointing toward the center and heat at $50^{\circ} \mathrm{C}$ was applied for $30 \mathrm{~s}$, then the applicator was moved to an adjacent area until the lesion had been completely covered, taking 4-5 min. The heat is completely localized and produced between the two electrodes of the applicator (an area approximately $3 \times 4 \mathrm{~mm}$ ). The lesion was then covered with a gauze bandage. No additional treatment was administered.

\subsubsection{Antimony treatment}

Intravenous injections of Glucantime, $20 \mathrm{mg} / \mathrm{kg} / \mathrm{d}$, were given during 20 consecutive days for all patients of the antimony group starting at day 0 and to all patients in the heat therapy group after day 28.

On day 14, the lesion was measured and signs of healing or secondary infection noted, and at that time another biopsy 
was taken for immunohistochemistry. The lesions were reevaluated on day 28 . Blood samples were taken for cytokine analysis on days 14 and 28 .

\subsubsection{Montenegro skin test}

At the first visit, a Montenegro skin test was applied to the volar face of the forearm of all patients. Test readings were made $48 \mathrm{~h}$ after application, and the size $(\mathrm{mm})$ of reaction was measured. These were considered positive when the induration was $5 \mathrm{~mm}$ in diameter or larger. The antigenic material used was a soluble extract antigen from $L$. (V.) braziliensis killed promastigotes as previously described (da Costa et al., 1996).

\subsubsection{Serology}

Patients' sera were tested for the presence of antiLeishmania antibodies by ELISA using a crude parasite antigen following the method previously described (Ashford et al., 1993).

\subsubsection{Determination of cytokines}

Peripheral blood mononuclear cells (PBMC) isolated from a ficoll-hypaque gradient (Pharmacia; Uppsala, Sweden) of heparinized venous blood PBMC were cultured in 24-well plates $5 \times 10^{6}$ cells/well in RPMI medium (Life Technologies, GIBCO-BRL, Gaithersburg, MD, USA) supplemented with $10 \%$ fetal calf serum (Hyclone, Logan, UT, USA), L-glutamine $(2 \mathrm{mmol} / \mathrm{l})$ sodium pyruvate $(1 \mathrm{mmol} / \mathrm{l})$, HEPES $(10 \mathrm{mmol} / \mathrm{l})$ and gentamycin $(50 \mu \mathrm{g} / \mathrm{ml})$ (Sigma, St Louis, MO, USA). Cultures were stimulated with $L$. (V.) braziliensis antigen prepared by freezing and thawing of axenic promastigotes three times. Cell-free supernatants were collected after $72 \mathrm{~h}$ of culture for cytokine analysis. Sandwich ELISA was carried out using antibody pairs from PharMingem (San Diego, CA, USA) and recombinant cytokines from R\&D (Minneapolis, MN, USA), following the manufacturers' instructions. Reaction was developed using 3,3',5,5'-tetramethylbenzidine (TMB peroxidase substrate; Kinkergaard \& Perry Laboratories, Gaithersburg, MD, USA) and read at $450 \mathrm{~nm}$.

\subsubsection{Immunohistochemistry for parasite detection} All biopsy fragments from skin lesions were fixed by tamponate $10 \%$ formalin, for $1-3 \mathrm{~d}$. After dehydration and paraffin embedding, serial sections of $3 \mu \mathrm{m}$ thickness were made, and immunohistochemistry was used to investigate the presence of amastigote forms of Leishmania in the lesions before and $14 \mathrm{~d}$ after treatment with Glucantime or heat therapy. A rabbit polyclonal antibody that recognizes different Leishmania species was used to identify amastigote forms. Although this antibody did not identify particular Leishmania species, it is known from previous studies in the region of the Jiquiriçá river valley in Bahia that $95 \%$ of $C L$ in this area is caused by L. (V.) braziliensis (Jones et al., 1987). Sections were incubated with a biotinylated anti-rabbit IgG followed by streptavidin-peroxidase conjugate, and the reaction was developed using diaminobenzidine (DAB). Parasitic diagnosis from the biopsies was confirmed in 27 of the patients $(12$ [71\%] of the heat therapy group and 15 [79\%] of the Glucantime group); the remainder had histopathology suggesting $\mathrm{CL}$, along with positive skin test and/or serology. A number of positive biopsies from 22 patients (14 in the Glucantime group and eight in the heat therapy group) were studied to compare the parasite load before and after treatment. The number of amastigotes seen in situ, before (in biopsy tissue by day 0) and after (in biopsy tissue by day 14) treatment, was determined according to intensity grades: (1) 1 to 10 amastigotes was considered as parasitism of mild intensity; (2) between 10 and 100 amastigotes was considered as parasitism of moderate intensity; and (3) above 100 amastigotes was considered as intense parasitism.

\subsection{Statistical analysis}

Data analysis was done using Epilnfo 6.04 (CDC, Atlanta, GA, USA) and SPSS (7.0 student version; SPSS Inc., Chicago, IL, USA) statistical software. Nonparametric statistical tests were used to allow for the lack of normality of the distribution of some variables considered in the study. Mann-Whitney and Kruskall-Wallis statistical analysis was used to test for differences between the two groups of treatment; the Wilcoxon signed-rank test was used to verify differences between cytokine levels before and after treatment. A $\chi^{2}$ test was applied to categorical variables. Graphics were constructed using Excel 97 (Microsoft, Redmond, WA, USA) and SPSS software.

\section{Results}

\subsection{Demographic and clinical baseline characteristics of patients}

The comparison of the demographic and clinical baseline characteristics of the two groups of patients is presented in Table 1. There were no statistical differences between the characteristics of the two groups, except that there were more patients with two lesions in the Glucantime group. Thus, randomization successfully allocated patients with similar characteristics into the two treatment groups. Further, no relation was demonstrated between Montenegro skin test, duration of active lesions and size of ulcers with Leishmania serology when tested by Kruskal-Wallis statistical analysis. Parasitic diagnosis from the biopsies was confirmed in 27 of the patients, 12 (71\%) of the heat therapy group and 15 (79\%) in the Glucantime group; the remainder had histopathology suggesting $\mathrm{CL}$, along with positive skin test and/or serology.

\subsection{Overall clinical response}

By day 28, most of the 37 patients were in the process of healing or had completely cured their lesions. One patient, however, who was treated with heat therapy, was excluded from analysis because he had put gunpowder over his ulcer and burned it several days after day 14 evaluation. Process of healing, as determined by decrease in size of the lesion and over $50 \%$ re-epithelization of the ulcer, was observed in $75 \%(12 / 16)$ of patients in the heat therapy group and $90 \%(18 / 20)$ in the Glucantime group. Three patients had complete cicatrization of the lesion: one in the heat therapy group and two in the Glucantime group. Three patients in the heat therapy group had no healing response seen by 
Table 1 Comparative baseline characteristics of 37 patients treated with heat therapy or Glucantime

\begin{tabular}{|c|c|c|c|c|}
\hline Patient characteristics & & $\begin{array}{l}\text { Heat therapy } \\
(n=17)\end{array}$ & $\begin{array}{l}\text { Glucantime } \\
(n=20)\end{array}$ & Statistical tests \\
\hline Age & Years (range) & $\begin{array}{l}34 \pm 14.6 \\
(18-65)\end{array}$ & $\begin{array}{l}36 \pm 17.2 \\
(18-67)\end{array}$ & $P=0.7078($ ANOVA $)$ \\
\hline \multirow[t]{2}{*}{ Gender } & Male, $n(\%)$ & $9(53)$ & $15(75)$ & $\begin{array}{l}P=0.2913 \chi^{2}=1.11 \text { (Yates' } \\
\text { corrected) }\end{array}$ \\
\hline & Female, $n(\%)$ & $8(47)$ & $5(25)$ & \\
\hline \multirow[t]{2}{*}{ Skin color } & White, $n(\%)$ & $6(35)$ & $8(40)$ & $\begin{array}{l}P=0.9633 \chi^{2}=0.00 \text { (Yates' } \\
\text { corrected) }\end{array}$ \\
\hline & Brown/black, $n(\%)$ & $11(65)$ & $12(60)$ & \\
\hline \multirow[t]{2}{*}{ Total no. lesions } & One, $n(\%)$ & $16(94)$ & $13(65)$ & $\begin{array}{l}P=0.0481 \chi^{2}=3.04 \text { (Yates' } \\
\text { corrected) }\end{array}$ \\
\hline & Two, $n(\%)$ & $1(6)$ & $7(35)$ & \\
\hline \multirow[t]{4}{*}{ Ulcer location } & Face, $n(\%)$ & 0 & $3(15)$ & $P=0.4276 \chi^{2}=2.78$ \\
\hline & Trunk, $n(\%)$ & $2(12)$ & $2(10)$ & \\
\hline & Upper limbs, $n(\%)$ & $3(18)$ & $3(15)$ & \\
\hline & Lower limbs, $n(\%)$ & $12(70)$ & $12(60)$ & \\
\hline Ulcer size & Mean \pm SD $(\mathrm{mm})$ & $23 \pm 9.3$ & $21 \pm 10.2$ & $P=0.784($ ANOVA $)$ \\
\hline Age of lesion (days) & Median (range) & $45(15-180)$ & $50(20-240)$ & $P=0.7799$ (Mann-Whitney) \\
\hline \multirow[t]{2}{*}{ Secondary infection ${ }^{a}$} & Present, $n(\%)$ & $4(24)$ & $9(45)$ & $\begin{array}{l}P=0.3087 \chi^{2}=1.04 \text { (Yates' } \\
\text { corrected) }\end{array}$ \\
\hline & Absent, $n(\%)$ & $13(76)$ & $11(55)$ & \\
\hline \multirow[t]{2}{*}{ Satellite ganglia ${ }^{a}$} & Present, $n(\%)$ & $10(58)$ & $15(75)$ & $\begin{array}{l}P=0.4869 \chi^{2}=0.48 \text { (Yates' } \\
\text { corrected) }\end{array}$ \\
\hline & Absent, $n(\%)$ & $7(42)$ & $5(25)$ & \\
\hline Montenegro test & Mean \pm SD $(\mathrm{mm})$ & $14.5 \pm 7$ & $17.7 \pm 10$ & $P=0.5896($ ANOVA $)$ \\
\hline \multirow[t]{2}{*}{ Leishmanial serology ${ }^{a}$} & Positive, $n(\%)$ & $14(82)$ & $32(86)$ & $P=0.3644 \chi^{2}=7.65$ \\
\hline & Negative, $n(\%)$ & $3(18)$ & $14(68)$ & \\
\hline \multirow[t]{2}{*}{ Amastigotes in biopsy ${ }^{a}$} & Present, $n(\%)$ & $12(71)$ & $15(79)$ & $\begin{array}{l}P=0.7060 \text { (Fisher's exact } \\
\text { test: } 2 \text {-tailed) }\end{array}$ \\
\hline & Absent, $n(\%)$ & $5(29)$ & $4(21)$ & \\
\hline
\end{tabular}

a Day 0.

day 28 evaluation. There was no significant statistical difference on the overall rate of response between the two groups $\left(\chi^{2}=4.14, P=0.1261\right)$. The size of ulcers was tested for association with the healing process by the two treatments, using $\chi^{2}$. There was no statistical evidence that size of ulcers influenced cicatrization.

No significant adverse effect was seen or reported by patients who submitted to heat therapy, except for secondary bacterial infection after treatment. A total of eight patients presented secondary bacterial infection, seven of them after heat therapy and one after Glucantime treatment (Yates' corrected $\chi^{2}=3.86, P=0.0351$, Fisher's exact test).

Of special interest, only one lesion of the patient with two lesions in the heat therapy group was heat-treated. Nevertheless, the untreated lesion on the opposite leg healed as rapidly as the treated lesion (Figure 1).

\subsection{Parasite burden determination in the lesions}

Comparative evolution of parasite burden between day 0 and day 14 in the treatment groups was analyzed using the Wilcoxon signed-rank test. In the Glucantime group, $64 \%$ of previously positive biopsies for Leishmania became negative on day $14(P=0.05)$. In the heat therapy group, $25 \%$ of previously positive biopsies became negative on day 14 $(P=0.131)$, and a reduction in intensity of parasitism was seen in two patients of this group. Both groups had similar intensity of parasitism in day 0 biopsies, as analyzed by Kruskal-Wallis test $(P=0.8947)$.

\subsection{Systemic cytokine response}

The results of cytokine production by PBMC (TNF- $\alpha$, IFN- $\gamma$, IL-5 and IL-10) were analyzed. A decrease in the levels of TNF- $\alpha$, IFN- $\gamma$ and IL- 5 comparing day 0 with day 28 was found in both groups: in the heat therapy group $(P=0.016, P=0.025$ and $P=0.013$, respectively) and in the Glucantime group ( $P=0.091, P=0.046$ and $P=0.075$, respectively) using the Wilcoxon signed-rank test (Figure 2). No statistically significant difference was found in IL-10 levels in either treatment group when day 0 was compared to day 28 . When comparing the cytokine levels of the two treatment groups, no statistically significant differences were found, as summarized in Table 2 (the lack of difference between the decreased IFN$\gamma$ levels of both groups was due to the variations in each group). 

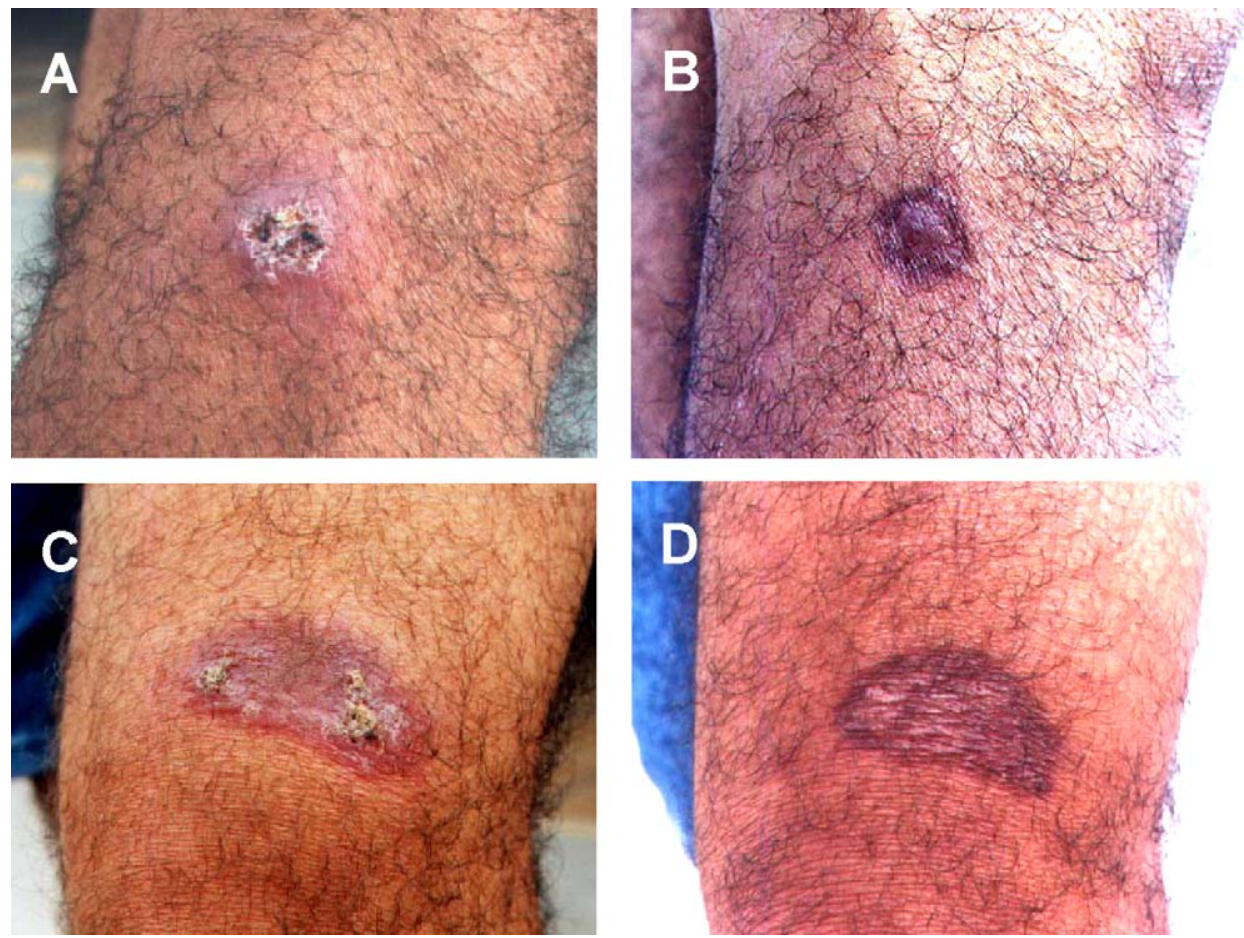

Figure 1 Systemic effect of heat therapy on cutaneous leishmaniasis (CL) lesion. Two CL lesions of a patient included in the heat therapy group. Heat-treated CL lesion at days 0 (A) and 28 (B). Contralateral untreated lesion at days 0 (C) and 28 (D).

Table 2 Comparative systemic cytokine responses in patients treated with heat therapy or Glucantime

\begin{tabular}{|c|c|c|c|c|c|c|c|c|c|c|c|c|}
\hline \multirow[t]{2}{*}{ Cytokine } & \multirow[t]{2}{*}{ Day } & \multicolumn{5}{|c|}{ Heat therapy } & \multicolumn{5}{|c|}{ Glucantime } & \multirow{2}{*}{$\begin{array}{l}\text { Mann-Whitney } \\
\text { test }\end{array}$} \\
\hline & & $n$ & Mean & SD & Median & Range & $n$ & Mean & SD & Median & Range & \\
\hline \multirow[t]{3}{*}{ IFN- $\gamma$} & 0 & 17 & 12.3 & 18.3 & 5.0 & $0-65$ & 20 & 8.5 & 17.2 & 3.4 & $0-67$ & $P=0.252$ \\
\hline & 14 & 15 & 5.5 & 7.5 & 1.2 & $0-24$ & 16 & 2.2 & 3.0 & 0.9 & $0-10$ & $P=0.544$ \\
\hline & 28 & 16 & 2.1 & 3.1 & 1.0 & $0-10$ & 16 & 5.7 & 10.3 & 1.0 & $0-35$ & $P=0.750$ \\
\hline \multirow[t]{3}{*}{ TNF- $\alpha$} & 0 & 17 & 3.7 & 5.1 & 2.0 & $0-20$ & 20 & 3.4 & 8.3 & 0.0 & $0-11$ & $P=0.252$ \\
\hline & 14 & 15 & 1.3 & 2.0 & 0.0 & $0-6$ & 16 & 1.0 & 2.7 & 0.0 & $0-11$ & $P=0.344$ \\
\hline & 28 & 16 & 0.25 & 0.4 & 0.0 & $0-1$ & 16 & 1.1 & 2.7 & 0.0 & $0-11$ & $P=0.269$ \\
\hline \multirow[t]{3}{*}{ IL- 5} & 0 & 17 & 38.9 & 53.3 & 25.0 & $0-218$ & 20 & 41.8 & 56.7 & 16.5 & $0-190$ & $P=0.756$ \\
\hline & 14 & 15 & 23.5 & 21.0 & 19.0 & $0-73$ & 16 & 14.1 & 25.2 & 5.0 & $0-100$ & $P=0.073$ \\
\hline & 28 & 16 & 15.1 & 16.6 & 10.5 & $0-45$ & 16 & 14.1 & 15.6 & 9.0 & $0-40$ & $P=0.873$ \\
\hline \multirow[t]{3}{*}{ IL-10 } & 0 & 17 & 137.5 & 97.1 & 112 & $0-295$ & 20 & 125.2 & 187.5 & 34.5 & $0-667$ & $P=0.146$ \\
\hline & 14 & 15 & 257.3 & 335.0 & 152.0 & $0-1010$ & 16 & 103.6 & 202.0 & 5.0 & $0-689$ & $P=0.139$ \\
\hline & 28 & 16 & 185.1 & 331.9 & 56.5 & $0-1185$ & 16 & 60.2 & 116.1 & 0.0 & $0-370$ & $P=0.176$ \\
\hline
\end{tabular}

\section{Discussion}

The results of this study show that a single local application of heat therapy to $C L$ lesions (radio waves induced by a ThermoSurgery instrument) will alter the production of systemic cytokines by PBMC similar to that seen by the systemic injection of Glucantime for $20 \mathrm{~d}$. Whether the alteration of the cytokine response is a direct result of the heat therapy and Glucantime, or a result of the healing process stimulated by the treatments, is not known at present. Further evidence of the systemic effect of heat therapy, however, is given below. In addition, this study confirms that heat therapy for $C L$ has beneficial effects similar to those of
Glucantime in this limited 28-day evaluation, confirming previous studies (Navin et al., 1990; Velasco-Castrejon et al., 1997).

The finding that Leishmania species, especially those causing $\mathrm{CL}$, are temperature-sensitive organisms (Berman and Neva, 1981; Sacks et al., 1983) has led to the use of heat for the treatment of cutaneous forms of leishmaniasis. Heat has been produced by the injection of bacteria (da Silveira and Brener, 1950) or applied directly to lesions using hot water (Neva et al., 1984), infrared (Junaid, 1986), ultrasound (Aram and Leibovici, 1987) and radio waves (Navin et al., 1990; Velasco-Castrejon et al., 1997). The delivery and control of the temperature, however, was previously 


\section{Glucantime}

IFN- $\gamma$

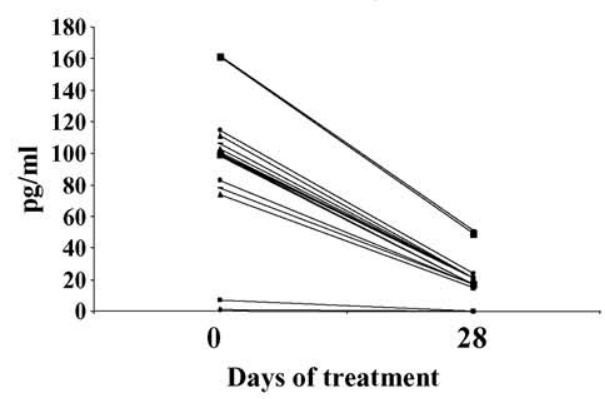

TNF- $\alpha$

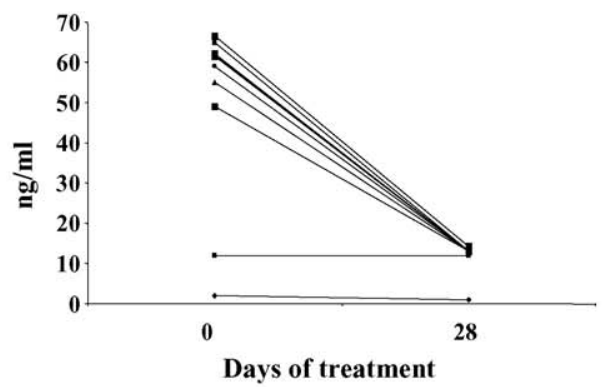

IL-5
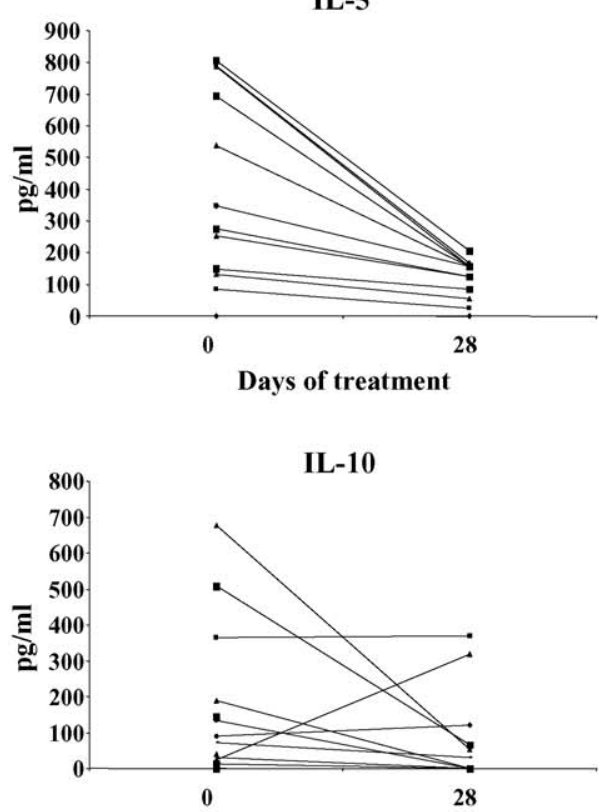

Days of treatment
Heat therapy

IFN- $\gamma$

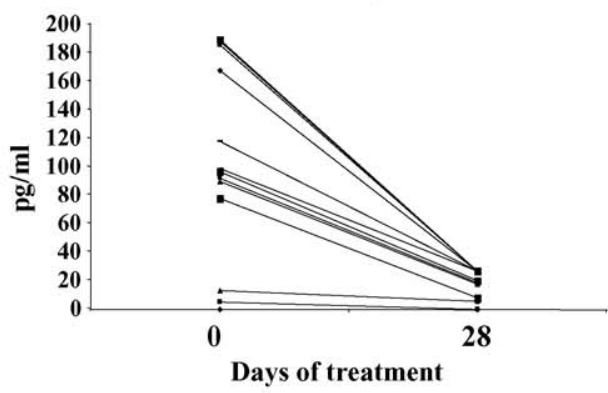

TNF- $\alpha$

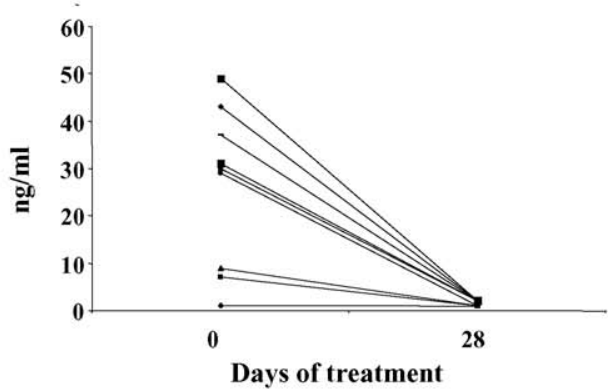

IL-5

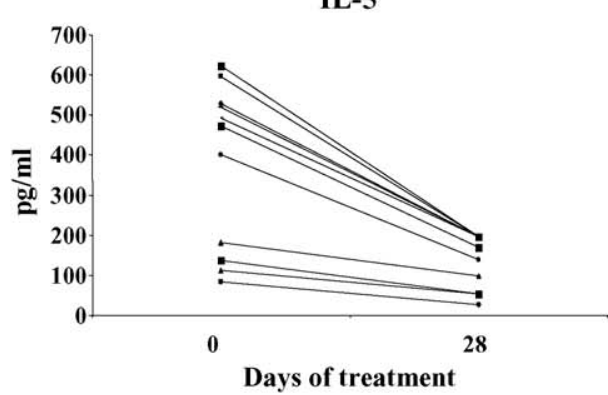

IL-10

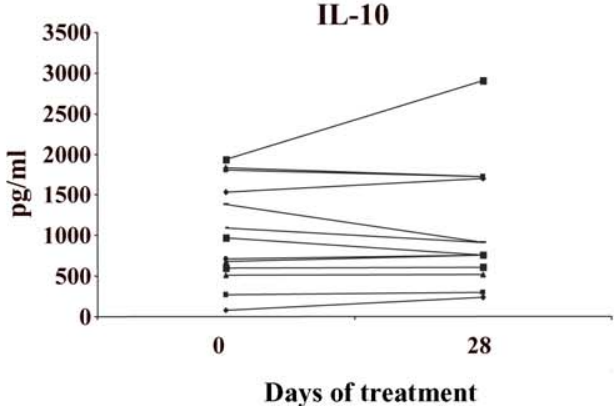

Figure 2 Cytokine response of peripheral blood mononuclear cells (PMBC) of patients treated with Glucantime or heat therapy. Levels of IFN- $\gamma$, TNF- $\alpha$, IL-5 and IL-10 in supernatants of PBMC stimulated with leishmanial antigen before (day 0$)$ and $28 \mathrm{~d}$ after heat therapy or Glucantime treatment.

a problem. This was mostly solved by the first ThermoSurgery instruments (Navin et al., 1990; Velasco-Castrejon et al., 1997), and especially in the latest model used in this study, which has an improved temperature control and sensor $\left(50 \pm 0.2^{\circ} \mathrm{C}\right)$.
The inflammatory response and control of infection in $\mathrm{CL}$ are mainly Th1-mediated. There is a polarity between the extreme inflammation of MCL with high IFN- $\gamma$ and TNF$\alpha$, the moderate inflammation in $\mathrm{CL}$, with less elevation of these cytokines and the absence of inflammation of $\mathrm{DCL}$ 
with low or lacking IFN- $\gamma$ (Bacellar et al., 2002; Bomfim et al., 1996; Castes et al., 1988; Follador et al., 2002). In our study, the production of IFN- $\gamma$ and TNF- $\alpha$ decreased following the therapies. Previous reports on the production of IFN $-\gamma$ and TNF- $\alpha$ in response to antimonial therapy has been variable, going down (Ribeiro-de-Jesus et al., 1998), not significantly altered (Coutinho et al., 1998) or raised, although lowered when chemotherapy was combined with immunotherapy (Toledo et al., 2001). In our study, the Th2 associated cytokines were either diminished (IL-5) or variable (IL-10) after $28 \mathrm{~d}$ of therapy. IL-10 is known to partially regulate $\mathrm{Th} 1$ responses, diminishing IFN- $\gamma$ production. Because IL-10 levels are low in MCL patients, in which IFN- $\gamma$ is the highest (Bacellar et al., 2002), the maintenance of IL10 after treatment of CL may be important in the prevention of MCL.

In addition to the controlled trial described above, seven $\mathrm{CL}$ patients resistant to Glucantime therapy were treated with heat. These patients were not healing after having being injected with as many as 80 to 100 or more ampoules of Glucantime. In every case, a dramatic healing response occurred to the heat therapy. Further, several CL patients who had to be excluded from the controlled trial because Glucantime was contraindicated (two pregnant women and one woman allergic to Glucantime) all responded well to heat therapy.

Further evidence for a systemic effect of heat therapy is the healing of the contralateral non-treated lesion in one patient included in the trial. In addition, a patient resistant to Glucantime who received heat therapy to one lesion had a contralateral non-treated lesion also heal. One patient with four lesions (that excluded him from the study) had one lesion treated and the three others cured simultaneously. The systemic effect on untreated lesions that also healed after heat therapy was previously reported by Junaid (1986). The mechanism for this distal healing is not known. Possibly, the leishmanial antigen released and incoming inflammatory cells at the burn site induce an immune response similar to a vaccine. Alternatively, the burn itself may cause the release of inflammatory molecules, which lead to the distal healing. A controlled study, designed to confirm that not all lesions on a patient need to be treated should be carried out, especially with patients having multiple $\mathrm{CL}$ lesions.

For the last 60 years, pentavalent antimony has been used as the drug of choice for the treatment of leishmaniasis (Marsden, 1985). It is well known that these compounds are toxic and that in some circumstances, as in localized single cutaneous lesions, the treatment can be more harmful than the disease (Convit et al., 1987). Many physicians no longer use pentavalent antimony because of its toxicity. Several alternatives have been tried, but so far none is considered convenient or efficacious enough to replace antimonial therapy. Heat therapy would appear to be a good alternative in $\mathrm{CL}$, as it is effective and usually requires only one application. In addition, the ThermoSurgery instrument can be taken into the field (it is a small equipment with an internal rechargeable battery). We now put antibiotic ointment on the lesion after the heat therapy to reduce the risk of bacterial infection.

In our trial, four patients had not responded to heat therapy at day 28 . We were unable to prolong the evaluation of heat therapy because everyone in that group received Glucantime after $28 \mathrm{~d}$ as part of the study design approved by the ethical committees. Now that a systemic effect of local heat therapy has been demonstrated, a large controlled trial involving heat therapy and Glucantime, with a 10-year follow-up, has been initiated by others in Ceará, Brazil to determine whether there is a difference in the incidence of MCL.

\section{Conflicts of interest statement}

The authors have no conflicts of interest concerning the work reported in this paper.

\section{Acknowledgements}

We wish to thank Gene Hedin for kindly supplying the ThermoSurgery instrument, the support of grants from NIH NIAID and the Fundação Bahiana de Infectologia in Salvador, Bahia. We also thank Martha Roper for contributions to the pilot project of this trial conducted in the endemic area of Laje, Jiquiriçá Valley, in Bahia, Brazil, and Raymundo Almeida, the mayor from Laje City in Bahia, who facilitated the fieldwork and the nurse at the Laje clinic.

\section{References}

Aram, H., Leibovici, V., 1987. Ultrasound-induced hyperthermia in the treatment of cutaneous leishmaniasis. Cutis 40, 350-353.

Ashford, D.A., Badaró, R., Eulálio, C., Freire, M., Miranda, C., Zalis, M.G., David, J.R., 1993. Studies on the control of visceral leishmaniasis: validation of the Falcon assay screening test-enzymelinked immunosorbent assay (FAST-ELISA) for field diagnosis of canine visceral leishmaniasis. Am. J. Trop. Med. Hyg. 48, 1-8.

Bacellar, O., Lessa, H., Schriefer, A., Machado, P., Ribeiro-deJesus, A., Dutra, W.O., Gollob, K.J., Carvalho, E.M., 2002. Up-regulation of Th1-type responses in mucosal leishmaniasis patients. Infect. Immun. 70, 6734-6740.

Berman, J.D., Neva, F.A., 1981. Effect of temperature on multiplication of Leishmania amastigotes within human monocyte-derived macrophages in vitro. Am. J. Trop. Med. Hyg. 30, 318-321.

Bomfim, G., Nascimento, C., Costa, J., Carvalho, E.M., BarralNetto, M., Barral, A., 1996. Variation of cytokine patterns related to therapeutic response in diffuse cutaneous leishmaniasis. Exp. Parasitol. 84, 188-194.

Castes, M., Cabrera, M., Trujillo, D., Convit, J., 1988. T-cell subpopulations, expression of interleukin-2 receptor, and production of interleukin-2 and gamma interferon in human American cutaneous leishmaniasis. J. Clin. Microbiol. 26, 1207-1213.

Convit, J., Castellanos, P.L., Rondon, A., Pinardi, M.E., Ulrich, M., Castes, M., Bloom, B., Garcia, L., 1987. Immunotherapy versus chemotherapy in localized cutaneous leishmaniasis. Lancet 21, 401-404.

Coutinho, S.G., Da-Cruz, A.M., Bertho, A.L., Santiago, M.A., DeLuca, P., 1998. Immunologic patterns associated with cure in human American cutaneous leishmaniasis. Braz. J. Med. Biol. Res. 31, 139-142.

da Costa, C.A., de Toledo, V.P., Genaro, O., Williams, P., Mayrink, W., 1996. Montenegro skin test-evaluation of the composition and stability of the antigen preparation. Mem. Inst. Oswaldo Cruz 91, 193-194.

da Silveira, M.R., Brener, Z., 1950. Nota preliminar sobre a piretoterapia na leishmaniose tegumentar americana. O Hospital (Rio de Janeiro) 37, 637-641. 
Heat therapy for cutaneous leishmaniasis

649

Follador, I., Araújo, C., Bacellar, O., Araujo, C.B., Carvalho, L.P., Almeida, R.P., Carvalho, E.M., 2002. Epidemiologic and immunologic findings for the subclinical form of Leishmania braziliensis infection. Clin. Infect. Dis. 34, E54-E58.

Jones, T.C., Johnson Jr., W.D., Barretto, A.C., Lago, E., Badaro, R., Cerf, B., Reed, S.G., Netto, E.M., Tada, M.S., Franca, T.F., 1987. Epidemiology of American cutaneous leishmaniasis due to Leishmania braziliensis braziliensis. J. Infect. Dis. 156, 73-83.

Junaid, A.J., 1986. Treatment of cutaneous leishmaniasis with infrared heat. Int. J. Dermatol. 25, 470-472.

Marsden, P.D., 1985. Pentavalent antimonial: old drug for new disease. Rev. Soc. Bras. Med. Trop. 18, 187-198.

Marsden, P.D., 1986. Mucosal Leishmaniasis 'espundia' Escomel, 1911. Trans. R. Soc. Trop. Med. Hyg. 80, 859-876.

Melby, P.C., Neva, F.A., Sacks, D.L., 1989. Profile of human T cell response to leishmanial antigens. Analysis by immunoblotting. J. Clin. Invest. 83, 1868-1875.

Navin, T.R., Arana, B.A., Arana, F.E., de Mérida, A.M., Castillo, A.L., Pozuelos, J.L., 1990. Placebo-controlled clinical trial of meglumine antimonate (glucantime) vs. localized controlled heat in the treatment of cutaneous leishmaniasis in Guatemala. Am. J. Trop. Med. Hyg. 42, 43-50.
Neva, F.A., Petersen, E.A., Corsey, R., Bogaert, H., Martinez, D., 1984. Observations on local heat treatment for cutaneous leishmaniasis. Am. J. Trop. Med. Hyg. 33, 800-804.

Ribeiro-de-Jesus, A., Almeida, R.P., Lessa, H., Bacellar, O., Carvalho, E.M., 1998. Cytokine profile and pathology in human leishmaniasis. Braz. J. Med. Biol. Res. 31, 143148.

Sacks, D.L., Barral, A., Neva, F.A., 1983. Thermosensitivity patterns of Old vs. New World cutaneous strains of Leishmania growing within mouse peritoneal macrophages in vitro. Am. J. Trop. Med. Hyg. 32, 300-304.

Toledo, V.P., Mayrink, W., Gollob, K.J., Oliveira, M.A., Costa, C.A., Genaro, O., Pinto, J.A., Afonso, L.C., 2001. Immunochemotherapy in American cutaneous leishmaniasis: immunological aspects before and after treatment. Mem. Inst. Oswaldo Cruz 96, 8998.

Velasco-Castrejon, O., Walton, B.C., Rivas-Sanchez, B., Garcia, M.F., Lazaro, G.J., Hobart, O., Roldan, S., Florian-Verdugo, J., Muguia-Saldana, A., Berzaluce, R., 1997. Treatment of cutaneous leishmaniasis with localized current field (radio frequency) in Tabasco. Mexico. Am. J. Trop. Med. Hyg. 57, 309312. 